\title{
Dealing with perceptions related to thrombosis and COVID-19 vaccines
}

To the Editor:

To date, there have been around 178 million confirmed SARS CoV-2 infections, and more than 3 million deaths worldwide. The global war against COVID-19 has been fought mainly in three battlegrounds: the hospitals, the communities, and in the minds of people. As populations around the globe still struggle to establish or keep the public health strategies needed, they also face an infodemic, especially regarding vaccines.

All vaccines can have rare adverse events, but during the pandemic, the report of isolated cases of blood clots associated to two of the anti-COVID vaccines that use adenovirus as a viral vector (AZD1222 and Johnson \& Johnson) have raised concerns in the population, as well as emergency reviews, safety signals, and vaccination pauses (1-4).

According to several reports, thrombosis associated to the AZD1222 vaccine occurred mainly in women under 55 years of age $(1,3)$. Some governments of high-income countries that have more than one vaccine type available, like the United Kingdom and Canada, have instructed to administer AZD1222 according to specific age groups of apparent less risk $(3,4)$. Others, like Denmark, stopped the use of that vaccine indefinitely (5).

Thrombosis after the two aforementioned COVID vaccines seems to be more common in women but almost non-existent in older adults, who could be the best candidates to receive them (1). This context shows that no vaccine can be discarded and illustrates that decisions regarding the use of available vaccines will improve as research and pharmacovigilance continues. Individual perceptions can influence the collective decision-making. Understanding that can help to reduce vaccine hesitancy, especially the one related to frequent alerts on adverse events.

The variety of options available for some high-income countries allows them to choose some vaccines over others, and they carry out such measures without jeopardizing their mass vaccination programs. On the other side, low and middle-income countries still lack access to vaccines. At the same time, the latter are generally weak in enforcing the most basic measures to contain the virus, their hospitals collapse rapidly, and they face challenges to even provide oxygen supply for patients in public settings.

From the global health perspective, fast and massive vaccination is a priority for all countries in order to get the herd immunity that can help stop the pandemic and its consequences. About one fifth of those who suffer from COVID-19 are at risk of a severe disease, and that is enough to bring any health system in the world to its knees. One key message for the public is that the benefit of vaccination far outweighs the risks, and that efforts are being made to reduce and treat this risk. According to several studies, the frequency of any type of thrombosis in COVID-19 can be up to 17.6\%(6), while initial data from the European Medicines Agency estimated a frequency of approximately 1 per 1,000,000 people vaccinated with the AZD1222 (1).

Regulatory offices and governments must keep an adequate and objective communication with citizens in order to reduce the reluctancetotheapplication of vaccines. Developed countries have more capacity to develop research and adequate pharmacovigilance systems for the early detection and treatment of adverse events. However, all countries should get that capacity, even if international support is necessary. Therefore, the alternative is to develop adequate pharmacovigilance systems, credibility and leadership from governments that work together with the population, a strategic education plan aided by scientists, participation of the media and political leaders, and to prepare healthcare systems to assist citizens in the immediate post vaccine period.

Vaccination together with public health measures will reflect on hospital occupation and economy recovery. Reaching most of the population with any available vaccine is also a time trial against the emergence of new variants of the virus that circumvent the immunity generated by vaccines.

Conflicts of interest. None declared.

Disclaimer. Authors hold sole responsibility for the views expressed in the manuscript, which may not necessarily reflect the opinion or policy of the RPSP/PAJPH or the Pan American Health Organization (PAHO).

\section{Céleo Ramírez}

Hospital del Valle, San Pedro Sula, Honduras

\section{Edwin F. Herrera Paz}

Universidad Católica de Honduras, San Pedro Sula, Honduras

\section{Sandra Gómez Ventura}

Consorcio de Investigadores COVID Honduras, Honduras

\section{Gaspar Rodríguez}

Consorcio de Investigadores COVID Honduras, Honduras

\section{Nery Linarez}

Hospital General del Sur, Choluteca, Honduras

\section{Reyna M. Durón}

Observatorio de COVID-19, Universidad Tecnológica Centroamericana, UNITEC Tegucigalpa, Honduras

$\triangle$ Reyna Durón, reyna.duron@unitec.edu.hn

Suggested citation Ramírez C, Herrera Paz EF, Gómez Ventura S, Rodríguez G, Linarez N, and Durón RM. Dealing with perceptions related to thrombosis and COVID-19 vaccines. Rev Panam Salud Publica. 2021;45:e45. https://doi.org/10.26633/RPSP.2021.45 


\section{REFERENCES}

1. European Medicines Agency. AstraZeneca's COVID-19 vaccine: EMA finds possible link to very rare cases of unusual blood clots with low blood platelets. Available at: https://www.ema.europa. $\mathrm{eu} / \mathrm{en} /$ news/astrazenecas-covid-19-vaccine-ema-finds-possiblelink-very-rare-cases-unusual-blood-clots-low-blood. Accessed May 2, 2021.

2. Centre for Disease Control. DC Joint CDC and FDA Statement on Johnson \& Johnson covid-19 vaccine. Available at: https://www. cdc.gov/media/releases/2021/s0413-JJ-vaccine.html. Date: April 13, 2021. Accessed May 2, 2021.

3. Medicines and Healthcare Products Regulatory Agency. MHRA issues new advice, concluding a possible link between COVID-19 Vaccine AstraZeneca and extremely rare, unlikely to occur blood clots. Available at: https:/ /www.gov.uk/government/news/mhraissues-new-advice-concluding-a-possible-link-between-covid-19vaccine-astrazeneca-and-extremely-rare-unlikely-to-occur-bloodclots. Accessed May 2, 2021.

4. National Advisory Committee on Immunization (NACI). AstraZeneca COVID-19 vaccine use in younger adults: NACI Recommendation-Canada 2021. Available at:https:/ / www.canada.ca/en/ public-health/services/immunization/national-advisory-committee- on-immunization-naci/rapid-response-recommended-useastrazeneca-covid-19-vaccine-younger-adults.html. Accessed May 2, 2021.

5. Danish Health Authority. Denmark continues its vaccine rollout without the COVID-19 vaccine from AstraZeneca. Danish Health Authority 2021. Available at: https://www.sst.dk/en/english/news/2021/ denmark-continues-its-vaccine-rollout-without-the-covid-19-vaccinefrom-astrazeneca. Accessed Apr 14, 2021.

6. Tan BK, Mainbourg S, Friggeri A, Bertoletti L, Douplat M, Dargaud Y, Grange C, Lobbes H, Provencher S, Lega JC. Arterial and venous thromboembolism in COVID-19: a study-level meta-analysis. Thorax. 2021; Published online Feb 23 2021. doi: 10.1136/thoraxjnl2020-215383.

Manuscript received on 7 May 2021; not peer-reviewed. Accepted on 7 June 2021. 